\title{
Discrimination Exposure and DNA Methylation of Stress-Related Genes in Latina Mothers
}

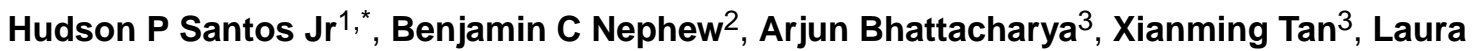 \\ Smith $^{4}$, Reema Alyamani ${ }^{4}$, Elizabeth M Martin ${ }^{5}$, Krista Perreira ${ }^{6}$, Rebecca C Fry ${ }^{7}$, and \\ Christopher Murgatroyd ${ }^{4}$
}

${ }^{1}$ School of Nursing, University of North Carolina at Chapel Hill, North Carolina, United States ${ }^{2}$ Department of Biology and Biotechnology, Worcester Polytechnic Institute, Worcester, MA, United States ${ }^{3}$ Department of Biostatistics, Gillings School of Global Public Health, University of North Carolina at Chapel Hill, North Carolina, United States ${ }^{4}$ School of Healthcare Science, Manchester Metropolitan University, Manchester, England ${ }^{5}$ Epigenetics and Stem Cell Biology Laboratory, National Institute of Environmental Health Sciences, Research Triangle Park, North Carolina, United States ${ }^{6}$ Department of Social Medicine, School of Medicine, University of North Carolina at Chapel Hill, North Carolina, United States ${ }^{7}$ Department of Environmental Sciences and Engineering, Curriculum in Toxicology, Gillings School of Global Public Health, University of North Carolina at Chapel Hill, North Carolina, United States

\section{Abstract}

Latina mothers, who have the highest fertility rate among all ethnic groups in the US, are often exposed to discrimination. The epigenetic changes related to this discrimination are largely unknown. This study is the first to explore the relationship between discrimination and DNA methylation of stress regulatory genes in Latinas. Our sample was Latina women $(n=147)$ with a mean age of 27.6 years who were assessed at 24-32 weeks' gestation (T1) and 4-6 weeks postpartum (T2) and reside in the U.S. Blood was collected at T1, and the Everyday Discrimination Scale (EDS) was administered at T1 and T2. DNA Methylation at candidate gene regions was determined by bisulphite pyrosequencing. Associations between EDS and DNA methylation were assessed via zero-inflated Poisson models, adjusting for covariates and multipletest comparisons. Discrimination was negatively associated with methylation at $\mathrm{CpG}$ sites within the glucocorticoid receptor $(N R 3 C 1)$ and brain-derived neurotrophic factor $(B D N F)$ genes that were consistent over time. In addition, discrimination was negatively associated with methylation

\footnotetext{
"Corresponding author: Hudson P Santos Jr, 120 N. Medical Drive, Carrington Hall, Campus Box \#7460, Chapel Hill, NC 27599-7460. hsantos@unc.edu, Phone: +1 (919) 966-9483.

Contributors: Authors HS, BN and CM designed the study. Authors HS, BN, LS, RA, and CM were involved in data collection, processing and/or quality assurance. Authors AB, XT, and HS performed the statistical analyses and/or made tables. All authors contributed to the interpretation of the results. Author HS wrote the first draft of the manuscript. All authors contributed to and have approved the final manuscript.

Conflict of interest: None.

Publisher's Disclaimer: This is a PDF file of an unedited manuscript that has been accepted for publication. As a service to our customers we are providing this early version of the manuscript. The manuscript will undergo copyediting, typesetting, and review of the resulting proof before it is published in its final citable form. Please note that during the production process errors may be discovered which could affect the content, and all legal disclaimers that apply to the journal pertain.
} 
of a $\mathrm{CpG}$ in the glucocorticoid binding protein $(F K B P 5)$ at $\mathrm{T} 1$ but not at $\mathrm{T} 2$. This study underscores associations between discrimination and epigenetic markers of DNA methylation in Latina women that warrant further investigation to better understand the biological pathways and psychopathological effects of discrimination on Latino mothers and their families.

\section{Keywords}

discrimination; stress; Hispanic/Latina; women's health; DNA methylation; epigenetics

\section{Introduction}

The accumulation of stress over the lifespan can contribute to biological vulnerability and directly affect health outcomes for mothers and their children. Latina women, who have the highest fertility rate among all ethnic groups and represent the largest minority group in the US (Center, 2015), are exposed to a multitude of stressful events and sociocultural factors, including discrimination (Ayón, 2015). Extant research in Latinas has largely focused on varied levels of exposure to risk and protective factors in the perinatal period including socio-determinants of health (e.g., socioeconomic background), prenatal care, social support, and stress. These factors, however, do not adequately account for all of the noted disparities in perinatal outcomes, such as perinatal depression and morbidity (Guintivano et al., 2017; Howell et al., 2017).

Discrimination has been defined as differential treatment based on: (1) race that disadvantages a racial/ethnic group and/or (2) inadequately justified factors other than race/ ethnicity that disadvantages a racial/ethnic group (Council, 2004). A contributing factor in health disparities and social inequality, discrimination has been associated with several adverse physical and mental health outcomes in minority groups (Wallace et al., 2016; Williams and Mohammed, 2009). A recent meta-analysis of 150 studies demonstrated a statistically significant effect size of racial discrimination on health, with the largest effect on mental health ( $\mathrm{r}=.20,95 \% \mathrm{CI}: .17, .24)$ (Carter et al., 2017). Earlier meta-analyses found similar associations (Lee and Ahn, 2012), and discrimination is a significant predictor of poor mental health in Black and Latino immigrants (Gee et al., 2006). A UK study concluded that cumulative exposure to racial discrimination has incremental long term effects, and noted that assessing discrimination at only one time point may underestimate the adverse effects of discrimination on mental health (Wallace et al., 2016). Among Latinos, discriminatory experiences are specifically associated with decreased self-esteem and emotional stress, increased anxiety and depressive symptoms, and social isolation (Ayón, 2015). A recent nationally representative survey suggested that one in three Latinos report discrimination based on ethnicity, and one in five report that they have avoided seeking medical care or calling police authorities because they were concerned that they or a family member would experience discrimination (Health et al., 2017). Overall, these studies suggest that Latinos face discrimination across the US. Moreover, in the current political climate, discrimination against Latinos may be increasing (Almeida et al., 2016). 
Several mechanisms for the adverse effects of discrimination on mental health have been described (Berger and Sarnyai, 2015). This study focuses on discrimination as a potent stressor that is associated with neuroendocrine dysregulation via epigenetic changes, specifically DNA methylation, of stress regulatory genes which can ultimately be linked to deleterious health effects. DNA methylation is the addition of a methyl group, usually to cytosines within $\mathrm{CpG}$ dinucleotides, which when located in promoter regions generally represses gene expression. Stress reactivity has been hypothesized to mediate the impact of the social environment on health. Social adversity, in animal and human studies, has potent dysregulatory effects, resulting in altered stress responsivity. Specifically, exposure to various environmental stressors can alter responses of the stress-regulatory hypothalamicpituitary-adrenal axis (HPA) through potentially enduring changes in the transcriptional regulation of key genes. Dysregulation of the stress response, through epigenetic modifications at key HPA-regulatory genes, is likely to contribute to stress-related health disparities and provide a link between the stressful social environment and disease development (Mitchell et al., 2016; Szyf, 2013).

Little is known about how perceived racial discrimination relates to DNA methylation patterning. A recent study reported an inverse relationship between perceived racial discrimination and DNA methylation at seven $\mathrm{CpG}$ sites (six genes related to tumor suppression protein-coding) in African-American women enrolled in a blood pressure study (Mendoza et al., 2018). To our knowledge, it is unknown if there are similar associations between discrimination and DNA methylation in Latinos. However, studies have reported dysregulation of the stress response in depressed Latina mothers (Lara-Cinisomo et al., 2017), supporting the rationale for the present investigation of discrimination and DNA methylation.

Two genes critically involved in the regulation of the stress response are the glucocorticoid receptor gene (NR3C1) (Herman et al., 2012) and the glucocorticoid receptor chaperone protein gene FKBP5, an important regulator of the stress response and glucocorticoid receptor sensitivity (Zannas et al., 2015). DNA methylation at key specific CpG sites within NR3C1 exon 1-F promoter has been associated with early adversity in a number of studies, supported by a meta-analysis (Palma-Gudiel et al., 2015). Early adversity has been associated with demethylation at two key CpGs within intron 7 of FKBP5, that appear to contribute to glucocorticoid resistance, higher cortisol levels, and prolonged recovery following exposure to stress, for review see Zannas and Binder (2014).

In addition, stress induced neuroplasticity associated with altered HPA function is mediated by functional interactions between glucocorticoids and brain-derived neurotrophic factor $(B D N F)$ (Numakawa et al., 2017) where methylation at a key promoter region IV has been linked to environmental stressors in humans and rodent models (Mitchelmore and Gede, 2014). Based on this integrated literature, we postulated that one biological mechanism related with discrimination is neuroendocrine-associated dysregulation via DNA methylation at previously described key $\mathrm{CpG}$ locis in stress regulatory genes. The current study investigated associations between methylation at specific $\mathrm{CpG}$ sites within the NR3C1, $F K B P 5$, and $B D N F$ genes and perceived discrimination during pregnancy and early postpartum in a population of Latina mothers. It was hypothesized that DNA methylation at 
key $\mathrm{CpG}$ sites within the $N R 3 C 1, F K B P 5$, and $B D N F$ genes is inversely associated with perceived discrimination in Latina women in the U.S.

\section{Material and Methods}

\subsection{Participants}

Healthy pregnant Latina women $(n=150)$ living in North Carolina $(\mathrm{NC})$ were enrolled in the study between May 2016 to March 2017. Eligibility criteria included: (1) 18-45 years old, (2) Spanish- or English-speaking, (3) carrying a singleton pregnancy, (4) available for follow-up at 6 weeks postpartum. Exclusion criteria were: (1) currently experiencing severe depressive symptoms as determined by psychiatric interview, (2) history of psychotic or bipolar disorder, or receiving psychotropic therapy, (3) substance dependence in the last two years, (4) fetal anomaly, or (5) life-threatening conditions. These exclusions were adopted to avoid confounders and control for severe mood symptoms with onset before the study time frame. Data collection was completed in English or Spanish, depending on participants preference, by a trained research assistant at the prenatal visit at 24-32-week gestation (T1) and at 4-6 weeks postpartum (T2). Measures used in this study had validated versions in English and Spanish. The Institutional Review Board of the University of North Carolina at Chapel Hill approved this study (\#15-3027).

\subsection{Measures}

2.2.1 Perceived Discrimination-The Everyday Discrimination Scale (EDS), a nineitem questionnaire, was used to measure routine, day-to-day experiences of discrimination at T1 and T2. The stem question is: "In your day-to-day life, how often do any of the following things happen to you?" Sample items include: "You are treated with less courtesy than other people are," "People act as if they think you are dishonest" and, "You are called names or insulted." Participants then link main reason for these discrimination experiences, including gender, race, ancestry, religion. In addition, participants were asked whether they have felt any type of ethnicity-based discrimination during their lifetime. The EDS is a widely used measure of subjective experiences of discrimination (Williams et al., 1997), with validated Spanish translation (Campo-Arias et al., 2015; Park et al., 2018). It correlates with measures of institutional racial discrimination and interpersonal prejudice (Krieger et al., 2005) and does not prime the subjects to think about race, which limits cues to prejudice prior to responding to the questions (Deitch et al., 2003). The 9-item Likert response scale for frequencies ranged from 0 ("never") to 5 ("almost every day"). We constructed a mean summary that ranged from 0 to 5 , with a higher score indicating a higher frequency of perceived discrimination. Cronbach's alpha for item consistency for the EDS in our sample was 0.86 for $\mathrm{T} 1$ and 0.89 for $\mathrm{T} 2$.

2.2.2 DNA Methylation-To minimize variability in stress, the study blood draw was incorporated into the routine prenatal blood draw at $\mathrm{T} 1$ followed by self-report measures. A $6 \mathrm{ml}$ blood sample was drawn from a peripheral vein into a chilled EDTA-vacutainer, placed immediately on ice and processed. The buffy coat was separated by centrifugation, frozen on dry ice, and stored at $-80^{\circ} \mathrm{C}$ at the University of North Carolina Biobehavioral lab until DNA extraction. DNA extraction was performed with the QIAamp DNA Blood Mini Kit and 
extracted DNA was stored at $-80^{\circ} \mathrm{C}$ in individual cryovials until shipment. The extracted DNA was transported on dry ice to the UK for DNA methylation analysis. DNA methylation levels were determined by bisulphite pyrosequencing (PCR). Briefly, $1 \mu \mathrm{g}$ DNA were treated using the EpiTect Bisulfite Kit (Qiagen) and candidate-gene regions containing specific CpGs within FKBP5 intron 7 (Paquette et al., 2014), BDNF untranslated exon IV (Perroud et al., 2013), and NR3C1 exon 1F (Murgatroyd et al., 2015) were amplified using the PyroMark PCR Kit. See Table 1 for primer sequences, locations of regions, and PCR conditions. We focused only on specific $\mathrm{CpGs}$ supported by previous literature to maintain statistical power and reduce effects of multiple analyses. Single-stranded biotinylated product was purified by mixing $10 \mu \mathrm{l}$ of the amplification mixture, $2 \mu \mathrm{l}$ of streptavidin sepharose HP (Amersham Biosciences), and $40 \mu \mathrm{l}$ of binding buffer. The sepharose beads containing the immobilized biotinylated product were purified, washed, and denatured in 0.2 $\mathrm{mol} / \mathrm{l} \mathrm{NaOH}$ and washed again using the Pyrosequencing Vacuum Prep Tool (Qiagen). The biotinylated DNA was resuspended in $12 \mu \mathrm{l}$ of annealing buffer containing $0.3 \mu \mathrm{mol} / \mathrm{l}$ pyrosequencing primer (see Table 1 for primer sequences) and quantified by pyrosequencing using the PSQ 24MA system with the PyroMark Q24 Advanced CpG Reagents (Qiagen). The percentage methylation for each of the $\mathrm{CpG}$ sites was calculated using Pyro Q-CpG software (Qiagen). All analyses represent the average of three separate assays.

2.2.3 Covariates-Maternal age, marital status, education, household income, ethnicity, years living in the US, nativity (US or non-US-born) and sex of the infant were collected through questionnaires at $\mathrm{T} 1$. We controlled for infant sex because previous literature suggests that newborn sex may be a key factor affecting the assimilation of prenatal stress into the epigenome (Braithwaite et al., 2015). These sex differences are likely to underlie the higher levels of glucocorticoids observed in females compared to males in response to acute and repeated stress (Seale et al., 2004). Because psychological distress is highly prevalent in Latina mothers and related to both discrimination and DNA methylation of stress-related genes (Berger and Sarnyai, 2015), we used the Inventory of Depression and Anxiety Symptoms - General Depression Scale (IDAS-GD) (Watson et al., 2012) which comprehensively assesses depressive symptoms to account for negative mood at T1 and T2; higher IDAS-GD scores indicates more severe symptoms. Typical IDAS-GD scores are 32.4 and 37.4 for control and high-risk women, respectively, and between 44.6 and 57.3 for depressed women (Schiller et al., 2013; Segre et al., 2015). Cronbach's alpha for item consistency for the IDAS-GD in our sample was $>0.78$ for T1 and T2.

2.2.4 Statistical Analysis-We set out to model the associations between DNA methylation in the prenatal period and concurrent and later EDS scores (outcome) with the goal of understanding their relationship over time. We modelled the composite EDS scores with zero-inflated Poisson (ZIP) models (Lambert, 1992) because of overdispersion sourced from a high frequency of zero counts in this score. The ZIP model fit the data more consistently than other models considered (i.e., negative binomial and zero-inflated negative binomial models). ZIP regression was used to model count data that has an excess of zero counts and assumes that the excess zeros can be modelled separately from the count values. Specifically, the ZIP regression model has two parts, a Poisson regression models for the counts, and a logistic model for excess of zeroes. In our study, the logistic model has only 
one covariate, IDAS-GD, as it was the only covariate associated with the excess zero process. We examined the association between $\mathrm{CpG}$ methylation and EDS by including specific CpG's in the Poisson model for counts, controlling for the variables of age, sex of baby, marital status, education, total income, ethnicity, years living in the US, and IDAS-GD score. Given our goal of identifying associations between DNA methylation at T1 and EDS at $\mathrm{T} 1$ and $\mathrm{T} 2$, we have chosen to retain the same set of covariates at T2, leaving DNA methylation as the primary covariate of interest in predicting EDS. We used the Vuong test (Vuong, 1989) to compare the ZIP with an ordinary Poisson regression model in terms of model fit. We used a post-hoc adjustment for multiple comparisons via the BenjaminiHochberg procedure and controlled for the false discovery rate of 0.05 . Only complete cases of covariates and control variables were considered $(n=147)$. Model goodness of fit was measured via McFadden pseudo- $\mathrm{R}^{2}$. McFadden pseudo- $\mathrm{R}^{2}$ measures the proportion of the variance in the outcome explained by the covariates, much like the coefficient of determination in an ordinary least squares (OLS) model. Instead of using sums of squared errors to construct $\mathrm{R}^{2}$, as in an OLS model, we used the log-likelihoods of the full and null models. We present Poisson model-based risk ratios associated with each $\mathrm{CpG}$ site and respective $p$-values, adjusted post-hoc via the Benjamini-Hochberg procedure, and McFadden pseudo- $\mathrm{R}^{2}$ values. To facilitate replication of this study, the $\mathrm{R}$ analytical code is available in Appendix A and the data can be downloaded from this link: https://osf.io/ am58g/.

2.2.5 Missing Data-A monotone missingness pattern was observed in follow-up (T2) IDAS-GD, and missing observations were multiply imputed with chained equations via predictive mean matching (White et al., 2011). Three observations with missing covariates and DNA methylation data for some of the markers were dropped from the study to avoid inducing bias due to imputation of both predictor and covariates.

\section{Results}

Table 2 summarizes the demographics of the cohort of 150 Latina women who were included in this analysis. The majority of our participants $(78.8 \%)$ chose to complete data collection in Spanish. Participants had a mean age of 27.6 years. Most participants were married or living with a partner (74.2\%), had an education level of high school or less $(85.0 \%)$, and had a yearly household income of $\leq 25,000$ US dollars (79.6\%). The majority were non-US born $(83.7 \%)$ and had been living in the US for a mean of 12 years. Of the sample, $56.3 \%$ were of Mexican origin, $17.2 \%$ were of Honduran origin, $13.3 \%$ were of Salvadoran origin, and the remaining $13.4 \%$ identified with other Latin American countries. In terms of depression symptoms from the IDAS-GD, the mean score was 29.87. In our sample, $43.5 \%$ of the women reported having experienced some type of discrimination (EDS $>0$ ), with $30.4 \%$ of the women specifically reported experiencing ethnicity-based discrimination at some point in their lives. For the EDS outcome, the mean scores were 0.34 (SD 0.56) and 0.22 (SD 0.46) at $\mathrm{T} 1$ and $\mathrm{T} 2$, respectively. The most frequently reported reasons for experiencing discrimination were race and ancestry at both time points (Table 3 ).

Evidence of one-way association between EDS and methylation at various sites suggested further modeling with potentially confounding variables (Appendix B, Figure 1). Vuong 
tests to compare non-nested models indicated that ZIP is a better fit to our data than ordinary Poisson regression, all with $p<0.001$. Table 4 shows the risk ratios between methylation at CpG site and EDS, estimated from the Poisson model part, controlling for all covariates listed previously (maternal age, marital status, education, household income, ethnicity, years living in the US, nativity, sex of the infant and mood symptoms). At T1, we found significant negative associations between EDS and methylation at CpG sites 1 and 2 of $N R 3 C 1$ ( $R R=0.85,0.84$ and $p=0.008,0.004$, respectively). Significant negative associations were also identified at $\mathrm{CpG}$ sites 6 and 7 of the $B D N F$ promoter $(\mathrm{RR}=0.86$, $0.92, p=0.004,0.004$, respectively). Lastly, a significant negative association at $\mathrm{CpG}$ site 1 of $F K B P 5$ was identified $(\mathrm{RR}=0.85, p<0.001)$. At $\mathrm{T} 1$, significant covariates were sex of the baby (associated with decreased EDS risk), and absence of a partner, income greater than US $\$ 40,000$, years living in the US, and depressive symptoms (associated with increased EDS risk).

We explored whether the relationship between DNAm and EDS hold at T2. Consistent with the findings at T1, the negative associations between EDS and CpG site 2 of $N R 3 C 1$ (RR = $0.84, p=0.025)$ and $\mathrm{CpG}$ sites 6 and 7 of $B D N F(\mathrm{RR}=0.89,0.92$, and $p=0.025,0.025$, respectively) were still present, suggesting these methylation markers should be further explored as correlates/predictors of discrimination-associated stress over time. The analysis also showed negative associations of EDS with $\mathrm{CpG}$ site 5 of $B D N F(\mathrm{RR}=0.86, p=0.025)$. At T2 significant covariates were age and presence of a partner (associated with decreased EDS risk), and income and general depression (associated with increased EDS risk). The complete model results from T1 and T2 are presented in Appendix B, tables B1-B4.

Considering the present results, we tested whether ethnicity-based discrimination was associated with DNA methylation for each $\mathrm{CpG}$ site in a post-hoc analysis. However, a basic test of association via logistic regression showed no association between average DNA methylation at these sites with perceived ethnic discrimination (Appendix B, Figure 2).

\section{Discussion}

This is the first study to report associations between blood DNA methylation of stressrelated genes ( $N R 3 C 1, F K B P 5, B D N F)$ and perceived discrimination in Latina women in the US. Exposure to discrimination has established adverse impacts on health. We hypothesized that DNA methylation within the NR3C1, FKBP5, and $B D N F$ genes would be inversely associated with perceived discrimination. In our cohort, $43.5 \%$ of the women reported having experienced discrimination of some sort. Via the EDS, women reported low to moderate frequency of discriminatory experience, which is consistent with a previous study (Colen et al., 2018), and related their discrimination experiences mostly to their race and ancestry. We identified several statistically significant associations, even after accounting for a stringent list of covariates, including demographics, ethnicity, immigration and mood symptoms. Our findings underscore the complex associations between discrimination and epigenetic modification in Latina women in the US.

Within the $N R 3 C 1$ exon $1 \mathrm{~F}$, methylation at $\mathrm{CpG}$ site 2 was negatively associated with EDS at both $\mathrm{T} 1$ and T2 while CpG 1 methylation was negatively associated with EDS at T1. The 
$N R 3 C 1$ exon $1 \mathrm{~F}$ is a key element in stress response regulation, and the present data suggest that increased EDS is associated with regulatory changes in glucocorticoid-related genes. The fewer associations at T2 are likely to be due to the 18-week gap between methylation levels at T1 and EDS assessment at T2. Other potential explanations, for further exploration, include the endocrine changes during the peripartum period (including elevated cortisol levels) and/or changes in EDS perception due to motherhood and associated improvements in the social environment (decreased exposure to negative social interactions, including discrimination, and increased exposure to social support). Our finding that some of the associations between DNA methylation and EDS score hold over time deserves further investigation. DNA methylation markers identified in the current study could serve as risk factors and/or biomarkers for mothers at risk of the adverse effects of discrimination if these changes in methylation mediate associated changes in social stress related responses to discrimination.

Differences in methylation patterns in the $N R 3 C 1$ exon $1 \mathrm{~F}$ (or Exon 17 in rats) in relation to social environment and stress have been reported in a systematic review of 40 articles (27 human and 13 animal studies) (Turecki and Meaney, 2016). In studies focused on psychological distress, human studies (seven in total) reported varied results in terms of NR3C1 exon 17 methylation: one reported increased methylation (Dammann et al., 2011), two reported decreased methylation (Alt et al., 2010; Yehuda et al., 2015), while three reported no change (Alt et al., 2010; Steiger et al., 2013; Yehuda et al., 2013). Similar findings were also reported in early life stress and parental stress studies. For example, in a socioeconomic-matched analysis of children exposed to maltreatment, researchers found decreased methylation in a single $\mathrm{CpG}(\mathrm{CpG} 2$, corresponding to our $\mathrm{CpG} 1)$ and increased methylation at CpGs 3, 5 and 6 (Romens et al., 2015). Another study found that maternal and paternal experience of the Holocaust were associated with decreased and increased methylation of exon 1F, respectively (Yehuda et al., 2014). A meta-analysis further demonstrated changes at specific $\mathrm{CpG} 36$ (corresponding to our $\mathrm{CpG} 1$ ) site and prenatal stress in infants supporting the importance of methylation at key $\mathrm{CpG}$ sites within NR3C1 (Palma-Gudiel et al., 2015). We hypothesize that Latinas that perceive higher levels of discrimination may not effectively down regulate glucocorticoid levels in response to this type of stress, resulting in increased susceptibility to adverse health outcomes. This discrimination exposure could be mediated by both genetic susceptibility and/or exposure to chronic stress. The current $N R 3 C 1$ methylation results indicate that changes in glucocorticoid methylation may be an important risk factor and support the investigation of this specific gene in long-term prospective and mechanistic studies to determine whether these epigenetic changes may lead to or result from long-term discrimination exposure.

Another important modulator of glucocorticoid signaling in response to stress is FKBPS, and the data suggest that the methylation of this glucocorticoid binding protein as well as the receptor gene are inversely associated with elevated EDS. The FKBPS and NR3C1 data together indicate that HPA related methylation changes are associated with both pre and postpartum discrimination, but the specific nature of this relationship may vary with time. The EDS and methylation findings support the hypothesis of increased responsiveness to social stress in subjects with higher EDS scores. One speculative implication of these data is that discrimination-related stress could induce coordinated DNA methylation effects on 
multiple genes that collectively serve to downregulate stress responsivity. However, a key consideration in these types of studies is that those who volunteer may tend to be relatively more resilient, less sensitive to discrimination, and express fewer psychological distress. While the design of the present study did not allow for causal mechanistic analyses, future studies should investigate the DNA methylation regulation of these stress-related genes in a larger and more heterogeneous cohort with a prospective design.

Significant negative associations between EDS and $B D N F$ methylation were also observed. BDNF is a major mediator of neuronal plasticity and there is substantial evidence that $B D N F$ expression and neurogenesis are generally reduced following chronic and acute stressors in human and animal studies. The negative association at T1 and T2 (CpGs 6 and 7) and potential increase in $B D N F$ in those exposed to higher levels of EDS may be driven by the type of BDNF actions associated with post-traumatic stress (Zhang et al., 2016), where increases may consolidate the behavioral effects of adverse stressful events through neuroplasticity mechanisms. It is interesting to note that behavioral and neural changes observed in mothers who experience a traumatic birth are similar to those found in patients with post-traumatic stress disorder (Yildiz et al., 2017).

A further point of discussion is whether discrimination might be positively adaptive in the sense of heightening awareness and attention to the environment. Such components of consciousness have been suggested to influence brain neuroplasticity, activating synaptic flow and changing brain structures and functional organization (Askenasy and Lehmann, 2013). The present data and the BDNF literature further underscore the imminent need for long-term prospective studies of the role of BDNF in the etiology of stress-related disorders in Latinas exposed to discrimination.

Looking at the covariates included in the regression models, we observed that sex of the baby (T1), age and presence of a partner (T2) all decreased the risk ratios for EDS, while depressive symptoms and higher annual income (T1 and T2), years living in the US and being single (T1) increasing the risk of discrimination. These findings reinforce reports of several risk factors for stress-related disorders and indicate that increased age and partner support may be particularly and specifically protective against the risk of discrimination in the perinatal period. Furthermore, increased risk associated with years living in the US may be due to impaired socio-cultural based resilience in these individuals (Cardoso and Thompson, 2010). The strikingly substantial increased risk of discrimination associated with greater income level extends the findings of previous studies showing an association between greater discrimination and increases in income (Colen et al., 2018). This suggests that potential benefits of the socioeconomic status gradient derived from greater income and education status may not be uniformly protective against social stressors, such as discrimination. Given the current methylation data, the association between depressive symptoms and EDS risk, and related research on the potency of discrimination as a social stressor, future studies should explore whether the relationship between discrimination and DNA methylation is mediated by HPA related factors and mechanisms. There is also a need to carefully consider social and temporal based characteristics of study populations to explore their potential effects between stress-related DNA methylation and discrimination. 
Given the evidence of the role of elevated cortisol levels in the adverse effects of discrimination on mental health (Berger and Sarnyai, 2015; Zeiders et al., 2012), the elevated prevalence of perinatal depression in Latinas (Gentile, 2017; Liu and Tronick, 2014), and the adverse effects of peripartum cortisol (Bergman et al., 2010), other stress related factors (Beijers et al., 2014) on offspring development and health, it is highly probable that discrimination can have negative effects on both mother and child. It is also possible that discrimination, as a robust and prevalent social stressor, may be a primary contributing factor in the high rates of Latina psychological distress (Halbreich and Karkun, 2006; Liu and Tronick, 2014). Assessment of discrimination in parents may serve as a sensitive and highly relevant indicator of elevated risk for perinatal depression and anxiety and the associated negative consequences on offspring.

Some limitations need to be taken into consideration while interpreting the results of this study. First, we focused on key CpGs to limit the potential impact of multiple analyses. However, there are many other $\mathrm{CpG}$ sites and combinations that could be explored. Second, we analyzed methylation within peripheral blood samples. We must consider that blood is heterogeneous, which may account for some of the variability in methylation and may introduce a confound where other variables are associated with cellular heterogeneity. Third, while studies combining methylation in blood and post mortem brain suggest that they are often substantially correlated (Tylee et al., 2013), it cannot be assumed that DNA methylation in peripheral tissues reflects methylation in relevant central nervous system regions. This is particularly a concern due to substantial variation in epigenetic effects across brain regions and cell types. Fourth, we used a self-reported measure of discrimination, thus introducing the risk of report bias. The EDS assesses discrimination across several domains, without specific reference to race, ethnicity or other demographic characteristics. This feature of the EDS allows it to be used across populations of different racial/ethnic backgrounds and also allows us to tap into the subjective experience of perceived discrimination (Lewis et al., 2012). While the overall sample size of 147 is modest, larger studies are needed to explore epigenome-wide analysis. Our data collection was completed between May 2016 to March 2017, which overlaps with the 2016 U.S. presidential election in which Latin American immigration to the US emerged as one of the most politicized and polemical topics on the campaign trail. Thus, it is possible that the reports obtained from our assessments, especially at T2 (post-election), were affected by the increased self-awareness and self-protection of Latinos within our communities, which could explain the small decrease in EDS report from T1 to T2. Answering reports based on social desirability prevents participants from increasing their interaction with the research team and related health care providers (Hopwood et al., 2009). In this sense, the EDS scores reported in this report are likely an underestimation of the actual experience of this population. Future studies should consider using multiple data collection methods to capture the complex nature of discrimination in an individual's life and social desirability on their approach to self-report social and health-related information. Lastly, our data cannot inform whether the methylation markers identified are specific to and/or caused by discrimination exposure, mechanistic and long-term prospective studies are needed to provide this type of evidence.

In summary, our findings indicate that discrimination exposure is inversely associated with DNA methylation intricately involved in the etiology of stress-related disorders, such as 
depression, anxiety, and post-traumatic stress, which substantially and disproportionally affect Latino communities. There were differences in methylation patterns within and across genes, emphasizing the importance of specificity in methylation patterns among $\mathrm{CpG}$ sites and reinforcing the call for studies to target $\mathrm{CpG}$ sites within biologically relevant areas, such as transcription factor binding regions and non-coding first exons of the $N R 3 C 1$ gene. In addition, there is a need for expression studies to determine the functional repercussions of $\mathrm{CpG}$ methylation. These results warrant further investigation to better understand the genetic and psychopathological effects of discrimination on Latino mothers and their families.

\section{Supplementary Material}

Refer to Web version on PubMed Central for supplementary material.

\section{Acknowledgements:}

We would to thank our research assistants, Erika Campos and Kathia Pena, for their effort in the recruitment and retention of participants in this study, and Victoria Benson for her effort in helping manage our samples in the UNC Biobehavioral Laboratory.

Role of funding source: This work was supported by the NIH Clinical and Translational Science Award, North Carolina Translational \& Clinical Sciences Institute (UL1TR001111; pilot grant \#550KR131619), and the Senich Innovation Award and the SPARK pilot program from the University of North Carolina at Chapel Hill School of Nursing. The content is solely the responsibility of the authors and does not represent the official views of the funding agencies.

\section{References}

1. Almeida J, Biello KB, Pedraza F, Wintner S, Viruell-Fuentes E, 2016 The association between antiimmigrant policies and perceived discrimination among Latinos in the US: A multilevel analysis. SSM - Population Health 2, 897-903. [PubMed: 29349196]

2. Alt SR, Turner JD, Klok MD, Meijer OC, Lakke EA, Derijk RH, Muller CP, 2010 Differential expression of glucocorticoid receptor transcripts in major depressive disorder is not epigenetically programmed. Psychoneuroendocrinology 35, 544-556. [PubMed: 19782477]

3. Askenasy J-J, Lehmann J, 2013 Consciousness, brain, neuroplasticity. Frontiers in Psychology 4.

4. Ayón C, 2015 Economic, Social, and Health Effects of Discrimination on Latino Immigrant Families. Migration Policy Institute, Washington, DC.

5. Beijers R, Buitelaar JK, de Weerth C, 2014 Mechanisms underlying the effects of prenatal psychosocial stress on child outcomes: beyond the HPA axis. Eur Child Adolesc Psychiatry 23, 943-956. [PubMed: 24875898]

6. Berger M, Sarnyai Z, 2015 "More than skin deep": stress neurobiology and mental health consequences of racial discrimination. Stress (Amsterdam, Netherlands) 18, 1-10.

7. Bergman K, Sarkar P, Glover V, O’Connor TG, 2010 Maternal Prenatal Cortisol and Infant Cognitive Development: Moderation by Infant-Mother Attachment. Biological psychiatry 67, 10261032. [PubMed: 20188350]

8. Braithwaite EC, Kundakovic M, Ramchandani PG, Murphy SE, Champagne FA, 2015 Maternal prenatal depressive symptoms predict infant NR3C1 1F and BDNF IV DNA methylation. Epigenetics 10, 408-417. [PubMed: 25875334]

9. Campo-Arias A, Herazo E, Oviedo HC, 2015 Escala de Discriminación en la Vida Cotidiana: Consistencia y estructura interna en estudiantes de medicina. Revista Médica de Risaralda 21, 3942. 
10. Cardoso JB, Thompson S, 2010 Common Themes of Resilience Among Latino Immigrant Families: A Systematic Review of the Literature. Families in Society: The Journal of Contemporary Social Services 91, 257-265.

11. Carter RT, Lau MY, Johnson V, Kirkinis K, 2017 Racial Discrimination and Health Outcomes Among Racial/Ethnic Minorities: A Meta-Analytic Review. Journal of Multicultural Counseling and Development 45, 232-259.

12. Center PR, 2015 Modern Immigration Wave Brings 59 Million to U.S., Driving Population Growth and Change Through 2065: Views of Immigration's Impact on U.S. Society Mixed. Pew Research Center, Washington, DC.

13. Colen CG, Ramey DM, Cooksey EC, Williams DR, 2018 Racial disparities in health among nonpoor African Americans and Hispanics: The role of acute and chronic discrimination. Social Science \& Medicine 199, 167-180. [PubMed: 28571900]

14. Council NR, 2004 Measuring Racial Discrimination. The National Academies Press, Washington, DC.

15. Dammann G, Teschler S, Haag T, Altmuller F, Tuczek F, Dammann RH, 2011 Increased DNA methylation of neuropsychiatric genes occurs in borderline personality disorder. Epigenetics 6, 1454-1462. [PubMed: 22139575]

16. Deitch EA, Barsky A, Butz RM, Chan S, Brief AP, Bradley JC, 2003 Subtle Yet Significant: The Existence and Impact of Everyday Racial Discrimination in the Workplace. Human Relations 56, 1299-1324.

17. Gee GC, Ryan A, Laflamme DJ, Holt J, 2006 Self-reported discrimination and mental health status among African descendants, Mexican Americans, and other Latinos in the New Hampshire REACH 2010 Initiative: the added dimension of immigration. Am J Public Health 96, 1821-1828. [PubMed: 17008579]

18. Gentile S, 2017 Untreated depression during pregnancy: Short- and long-term effects in offspring. A systematic review. Neuroscience 342, 154-166. [PubMed: 26343292]

19. Guintivano J, Sullivan PF, Stuebe AM, Penders T, Thorp J, Rubinow DR, Meltzer-Brody S, 2017 Adverse life events, psychiatric history, and biological predictors of postpartum depression in an ethnically diverse sample of postpartum women. Psychol Med, 1-14.

20. Halbreich U, Karkun S, 2006 Cross-cultural and social diversity of prevalence of postpartum depression and depressive symptoms. J Affect Disord 91, 97-111. [PubMed: 16466664]

21. Health H.T.H.C.S.o.P., Radio NP, Foundation RWJ, 2017 Discrimination in America: Experiences and Views of Latinos.

22. Herman JP, McKlveen JM, Solomon MB, Carvalho-Netto E, Myers B, 2012 Neural regulation of the stress response: glucocorticoid feedback mechanisms. Brazilian Journal of Medical and Biological Research 45, 292-298. [PubMed: 22450375]

23. Hopwood CJ, Flato CG, Ambwani S, Garland BH, Morey LC, 2009 A comparison of Latino and Anglo socially desirable responding. J Clin Psychol 65, 769-780. [PubMed: 19388057]

24. Howell EA, Egorova NN, Janevic T, Balbierz A, Zeitlin J, Hebert PL, 2017 Severe Maternal Morbidity Among Hispanic Women in New York City: Investigation of Health Disparities. Obstetrics and gynecology 129, 285-294. [PubMed: 28079772]

25. Krieger N, Smith K, Naishadham D, Hartman C, Barbeau EM, 2005 Experiences of discrimination: validity and reliability of a self-report measure for population health research on racism and health. Social science \& medicine (1982) 61, 1576-1596. [PubMed: 16005789]

26. Lambert D, 1992 Zero-Inflated Poisson Regression, with an Application to Defects in Manufacturing. Technometrics 34, 1-14.

27. Lara-Cinisomo S, Grewen KM, Girdler SS, Wood J, Meltzer-Brody S, 2017 Perinatal Depression, Adverse Life Events, and Hypothalamic-Adrenal-Pituitary Axis Response to Cold Pressor Stress in Latinas: An Exploratory Study. Women's Health Issues 27, 673-682. [PubMed: 28780256]

28. Lee DL, Ahn S, 2012 Discrimination Against Latina/os:A Meta-Analysis of Individual-Level Resources and Outcomes. The Counseling Psychologist 40, 28-65.

29. Lewis TT, Yang FM, Jacobs EA, Fitchett G, 2012 Racial/Ethnic Differences in Responses to the Everyday Discrimination Scale: A Differential Item Functioning Analysis. American Journal of Epidemiology 175, 391-401. [PubMed: 22306556] 
30. Liu CH, Tronick E, 2014 Prevalence and predictors of maternal postpartum depressed mood and anhedonia by race and ethnicity. Epidemiology and psychiatric sciences 23, 201-209. [PubMed: 23931673]

31. Mendoza V.B.d., Huang Y, Crusto CA, Sun YV, Taylor JY, 2018 Perceived Racial Discrimination and DNA Methylation Among African American Women in the InterGEN Study. Biological Research For Nursing 20, 145-152. [PubMed: 29258399]

32. Mitchell C, Schneper LM, Notterman DA, 2016 DNA methylation, early life environment, and health outcomes. Pediatric research 79, 212-219. [PubMed: 26466079]

33. Mitchelmore C, Gede L, 2014 Brain derived neurotrophic factor: Epigenetic regulation in psychiatric disorders. Brain Research 1586, 162-172. [PubMed: 25223903]

34. Murgatroyd C, Quinn JP, Sharp HM, Pickles A, Hill J, 2015 Effects of prenatal and postnatal depression, and maternal stroking, at the glucocorticoid receptor gene. Transl Psychiatry 5, e560. [PubMed: 25942041]

35. Numakawa T, Odaka H, Adachi N, 2017 Actions of Brain-Derived Neurotrophic Factor and Glucocorticoid Stress in Neurogenesis. International Journal of Molecular Sciences 18, 2312.

36. Palma-Gudiel H, Cordova-Palomera A, Leza JC, Fananas L, 2015 Glucocorticoid receptor gene (NR3C1) methylation processes as mediators of early adversity in stress-related disorders causality: A critical review. Neurosci Biobehav Rev 55, 520-535. [PubMed: 26073068]

37. Paquette AG, Lester BM, Koestler DC, Lesseur C, Armstrong DA, Marsit CJ, 2014 Placental FKBP5 genetic and epigenetic variation is associated with infant neurobehavioral outcomes in the RICHS cohort. PLoS One 9, e104913. [PubMed: 25115650]

38. Park IJK, Du H, Wang L, Williams DR, Alegría M, 2018 Racial/Ethnic Discrimination and Mental Health in Mexican-Origin Youths and Their Parents: Testing the "Linked Lives" Hypothesis. Journal of Adolescent Health 62, 480-487. [PubMed: 29275862]

39. Perroud N, Salzmann A, Prada P, Nicastro R, Hoeppli ME, Furrer S, Ardu S, Krejci I, Karege F, Malafosse A, 2013 Response to psychotherapy in borderline personality disorder and methylation status of the BDNF gene. Translational Psychiatry 3, e207. [PubMed: 23422958]

40. Romens SE, McDonald J, Svaren J, Pollak SD, 2015 Associations between early life stress and gene methylation in children. Child Dev 86, 303-309. [PubMed: 25056599]

41. Schiller CE, O'Hara MW, Rubinow DR, Johnson AK, 2013 Estradiol modulates anhedonia and behavioral despair in rats and negative affect in a subgroup of women at high risk for postpartum depression. Physiology \& behavior 119, 137-144. [PubMed: 23770328]

42. Seale JV, Wood SA, Atkinson HC, Bate E, Lightman SL, Ingram CD, Jessop DS, Harbuz MS, 2004 Gonadectomy Reverses The Sexually Diergic Patterns Of Circadian and Stress-Induced Hypothalamic-Pituitary-Adrenal Axis Activity In Male and Female Rats. Journal of Neuroendocrinology 16, 516-524. [PubMed: 15189326]

43. Segre LS, Brock RL, O’Hara MW, 2015 Depression Treatment for Impoverished Mothers by Point-of-Care Providers: A Randomized Controlled Trial. Journal of consulting and clinical psychology 83, 314-324. [PubMed: 25486371]

44. Steiger H, Labonte B, Groleau P, Turecki G, Israel M, 2013 Methylation of the glucocorticoid receptor gene promoter in bulimic women: associations with borderline personality disorder, suicidality, and exposure to childhood abuse. The International journal of eating disorders 46, $246-$ 255. [PubMed: 23417893]

45. Szyf M, 2013 Social Environment and DNA Methylation: A Mechanism for Linking Nurture and Nature, in: Jirtle RL, Tyson FL (Eds.), Environmental Epigenomics in Health and Disease: Epigenetics and Complex Diseases. Springer Berlin Heidelberg, Berlin, Heidelberg, pp. 21-35.

46. Turecki G, Meaney M, 2016 Effects of the social environment and stress on glucocorticoid receptor gene methylation: a systematic review. Biological psychiatry 79, 87-96. [PubMed: 25687413]

47. Tylee DS, Kawaguchi DM, Glatt SJ, 2013 On the outside, looking in: a review and evaluation of the comparability of blood and brain “-omes". American journal of medical genetics. Part B, Neuropsychiatric genetics : the official publication of the International Society of Psychiatric Genetics 162b, 595-603.

48. Vuong QH, 1989 Likelihood Ratio Tests for Model Selection and Non-Nested Hypotheses. Econometrica 57, 307-333. 
49. Wallace S, Nazroo J, Becares L, 2016 Cumulative Effect of Racial Discrimination on the Mental Health of Ethnic Minorities in the United Kingdom. Am J Public Health 106, 1294-1300. [PubMed: 27077347]

50. Watson D, O’Hara MW, Naragon-Gainey K, Koffel E, Chmielewski M, Kotov R, Stasik SM, Ruggero CJ, 2012 Development and validation of new anxiety and bipolar symptom scales for an expanded version of the IDAS (the IDAS-II). Assessment 19, 399-420. [PubMed: 22822173]

51. White IR, Royston P, Wood AM, 2011 Multiple imputation using chained equations: Issues and guidance for practice. Statistics in Medicine 30, 377-399. [PubMed: 21225900]

52. Williams DR, Mohammed SA, 2009 Discrimination and racial disparities in health: evidence and needed research. Journal of behavioral medicine 32, 20. [PubMed: 19030981]

53. Williams DR, Yu Yan, Jackson JS, Anderson NB, 1997 Racial Differences in Physical and Mental Health: Socio-economic Status, Stress and Discrimination. J Health Psychol 2, 335-351. [PubMed: 22013026]

54. Yehuda R, Daskalakis NP, Desarnaud F, Makotkine I, Lehrner AL, Koch E, Flory JD, Buxbaum JD, Meaney MJ, Bierer LM, 2013 Epigenetic Biomarkers as Predictors and Correlates of Symptom Improvement Following Psychotherapy in Combat Veterans with PTSD. Front Psychiatry 4, 118. [PubMed: 24098286]

55. Yehuda R, Daskalakis NP, Lehrner A, Desarnaud F, Bader HN, Makotkine I, Flory JD, Bierer LM, Meaney MJ, 2014 Influences of maternal and paternal PTSD on epigenetic regulation of the glucocorticoid receptor gene in Holocaust survivor offspring. Am J Psychiatry 171, 872-880. [PubMed: 24832930]

56. Yehuda R, Flory JD, Bierer LM, Henn-Haase C, Lehrner A, Desarnaud F, Makotkine I, Daskalakis NP, Marmar CR, Meaney MJ, 2015 Lower methylation of glucocorticoid receptor gene promoter $1 \mathrm{~F}$ in peripheral blood of veterans with posttraumatic stress disorder. Biol Psychiatry 77, 356-364. [PubMed: 24661442]

57. Yildiz PD, Ayers S, Phillips L, 2017 The prevalence of posttraumatic stress disorder in pregnancy and after birth: A systematic review and meta-analysis. J Affect Disord 208, 634-645. [PubMed: 27865585]

58. Zannas AS, Binder EB, 2014 Gene-environment interactions at the FKBP5 locus: sensitive periods, mechanisms and pleiotropism. Genes, brain, and behavior 13, 25-37.

59. Zannas AS, Wiechmann T, Gassen NC, Binder EB, 2015 Gene-Stress-Epigenetic Regulation of FKBP5: Clinical and Translational Implications. Neuropsychopharmacology 41, 261. [PubMed: 26250598]

60. Zeiders KH, Doane LD, Roosa MW, 2012 Perceived Discrimination and Diurnal Cortisol: Examining Relations among Mexican American Adolescents. Hormones and Behavior 61, 541548. [PubMed: 22342577]

61. Zhang L, Li XX, Hu XZ, 2016 Post-traumatic stress disorder risk and brain-derived neurotrophic factor Val66Met. World J Psychiatry 6, 1-6. [PubMed: 27014593] 


\section{Highlights}

- DNA methylation of genes implicated in stress-related disorders predicts discrimination

- Discrimination is inversely associated with $N R 3 C 1$ and $B D N F$ methylation over time

- $\quad$ Discrimination is inversely associated with FKBP5 methylation at $\mathrm{T} 1$ but not at $\mathrm{T} 2$

- $\quad B D N F$ data support the hypothesis of discrimination associated neuroplasticity 


\section{롤 \\ 골}

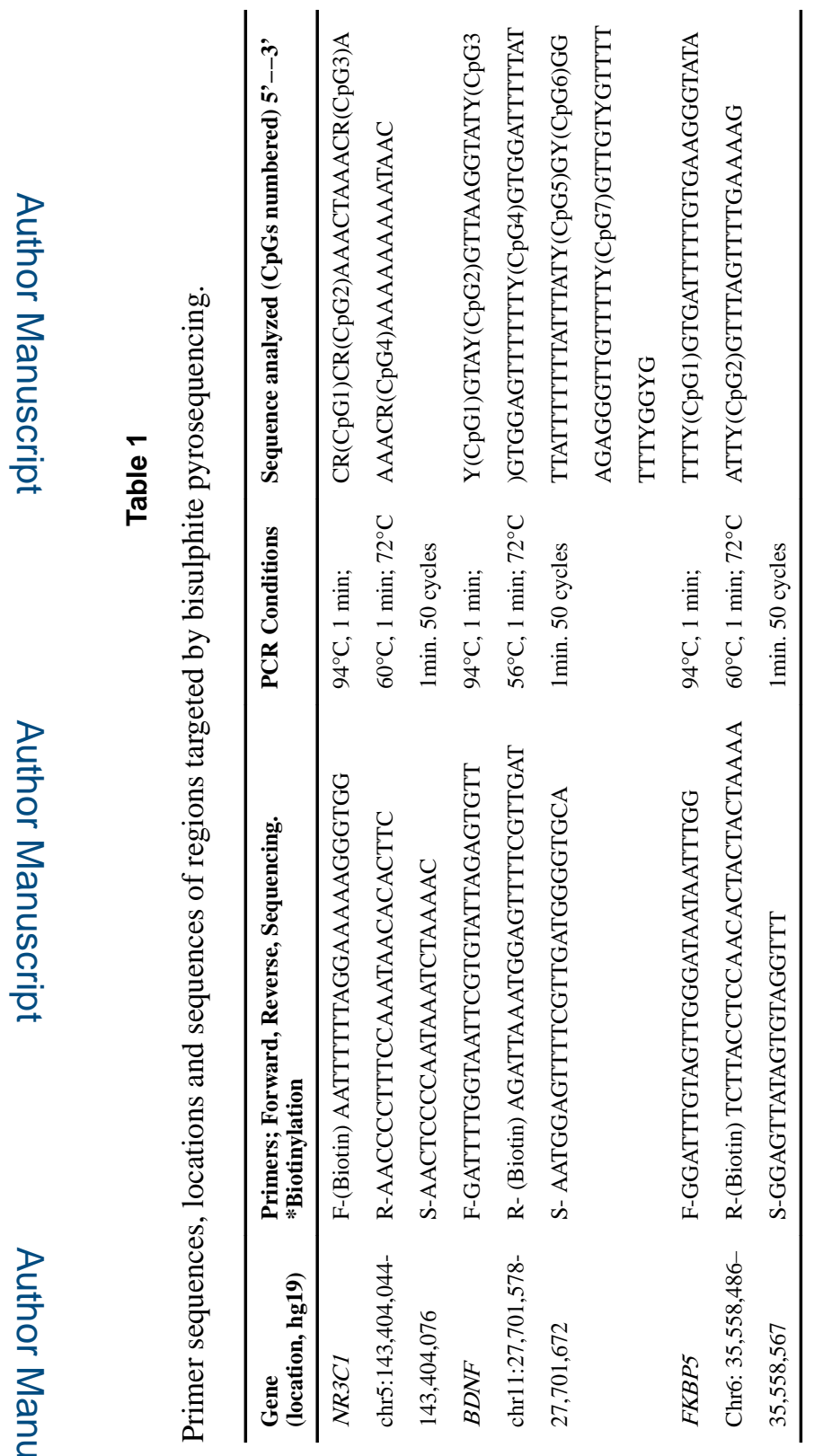




\section{Table 2}

Baseline characteristics of the cohort $(n=147)$.

\begin{tabular}{|c|c|}
\hline \multicolumn{2}{|l|}{ Age, years } \\
\hline Mean (SD) & $27.6(6.35)$ \\
\hline \multicolumn{2}{|l|}{ Marital status } \\
\hline Married & $34.7 \%$ \\
\hline Not married but living with partner & $39.5 \%$ \\
\hline Single & $25.8 \%$ \\
\hline \multicolumn{2}{|l|}{ Education } \\
\hline High school or less & $85.0 \%$ \\
\hline Some college & $8.2 \%$ \\
\hline Other & $6.8 \%$ \\
\hline \multicolumn{2}{|l|}{ Household income (Yearly) } \\
\hline$<\$ 25,000$ & $79.6 \%$ \\
\hline$\$ 25,000-39,999$ & $19.7 \%$ \\
\hline$>\$ 40,000$ & $0.7 \%$ \\
\hline \multicolumn{2}{|l|}{ Nativity } \\
\hline Non-US born & $83.7 \%$ \\
\hline US-born & $16.3 \%$ \\
\hline \multicolumn{2}{|l|}{ Years living in US } \\
\hline Mean (SD) & $12.0(7.27)$ \\
\hline \multicolumn{2}{|l|}{ Sex of the infant } \\
\hline Male & $46.3 \%$ \\
\hline Female & $53.7 \%$ \\
\hline \multicolumn{2}{|l|}{ Parity } \\
\hline 0 children & $35.1 \%$ \\
\hline $1-2$ children & $41.6 \%$ \\
\hline$\geq 3$ children & $20.4 \%$ \\
\hline \multicolumn{2}{|l|}{ Country of Origin } \\
\hline Mexico & $56.3 \%$ \\
\hline Honduras & $17.2 \%$ \\
\hline El Salvador & $13.2 \%$ \\
\hline Other & $13.4 \%$ \\
\hline \multicolumn{2}{|l|}{ Gestational Age at T1 } \\
\hline Mean (SD) & $28.81(1.28)$ \\
\hline \multicolumn{2}{|l|}{ Postpartum weeks at T2 } \\
\hline Mean (SD) & $4.9(1.01)$ \\
\hline \multicolumn{2}{|l|}{ Depression Symptoms (IDAS-GD T1) } \\
\hline Mean (SD) & $30.77(6.31)$ \\
\hline \multicolumn{2}{|l|}{ Depression Symptoms (IDAS-GD T2) } \\
\hline Mean (SD) & $29.87(7.20)$ \\
\hline
\end{tabular}

Psychoneuroendocrinology. Author manuscript; available in PMC 2019 December 01. 


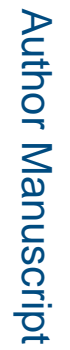

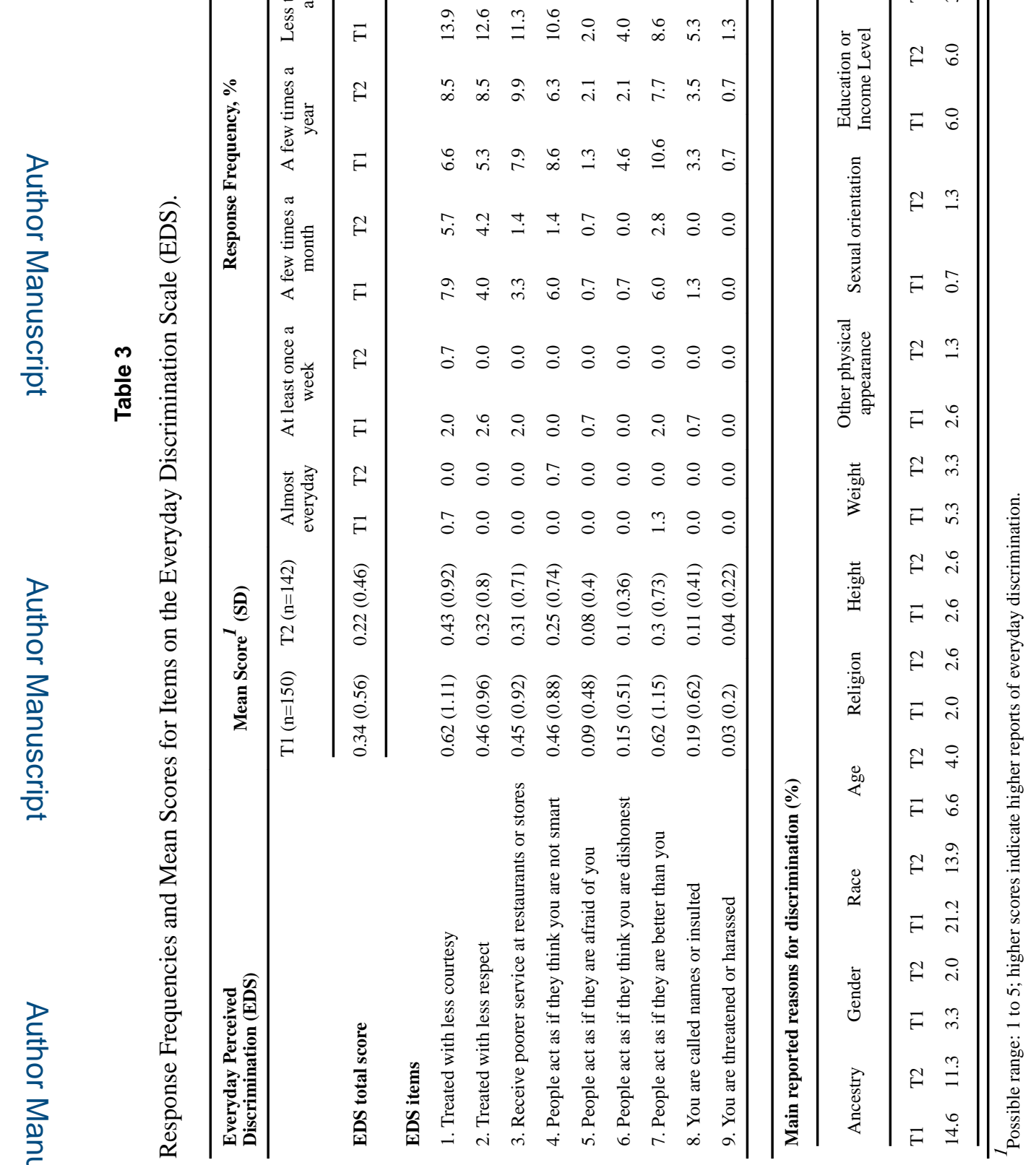




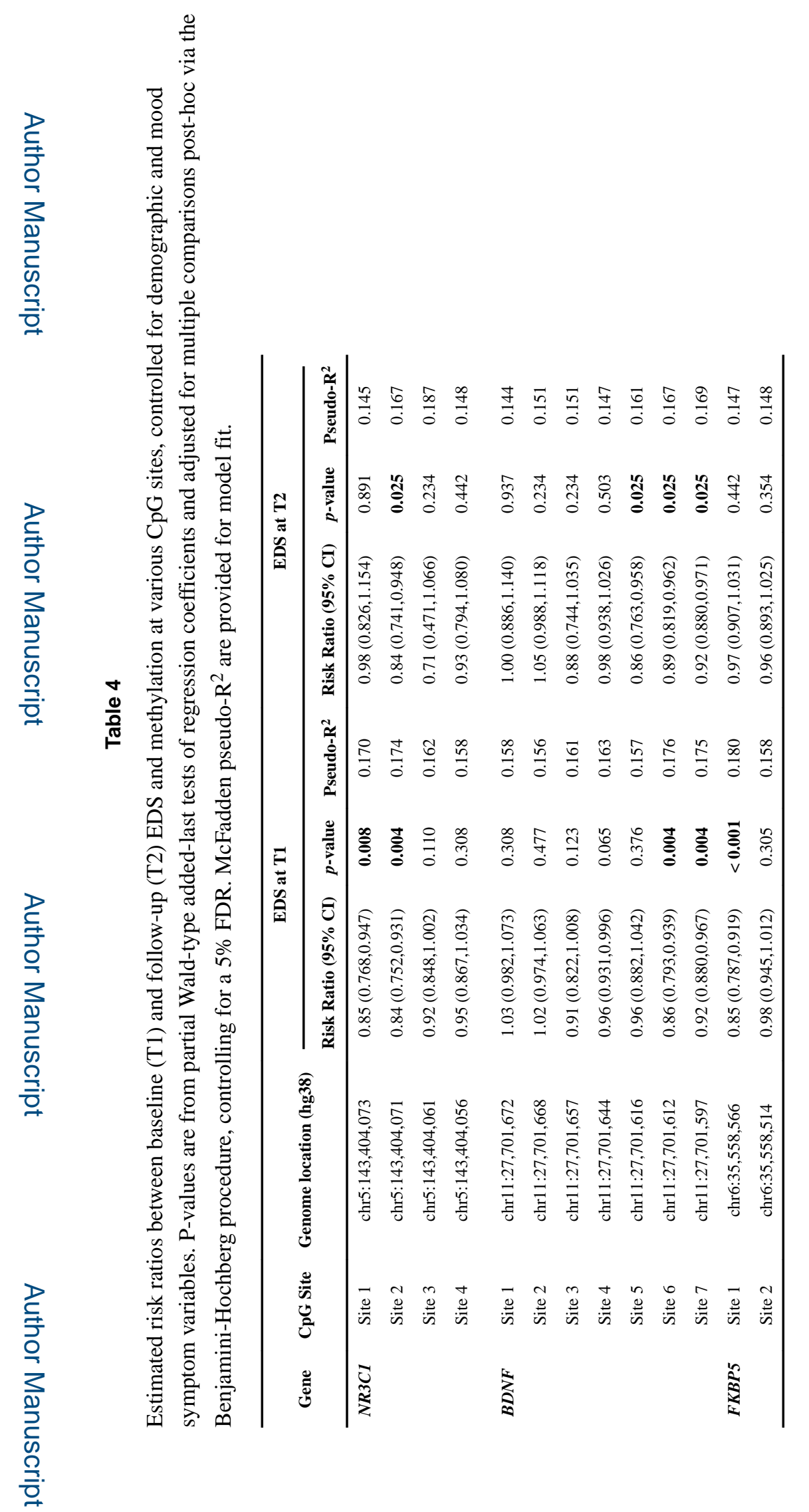

Psychoneuroendocrinology. Author manuscript; available in PMC 2019 December 01. 